\title{
Unsteady Hydromagnetic Flow of Radiating Fluid Past a Convectively Heated Vertical Plate with the Navier Slip
}

\author{
O. D. Makinde and M. S. Tshehla \\ Faculty of Military Science, Stellenbosch University, Private Bag X2, Saldanha 7395, South Africa \\ Correspondence should be addressed to O. D. Makinde; makinded@gmail.com
}

Received 17 February 2014; Accepted 3 April 2014; Published 17 April 2014

Academic Editor: Raseelo Joel Moitsheki

Copyright ( 2014 O. D. Makinde and M. S. Tshehla. This is an open access article distributed under the Creative Commons Attribution License, which permits unrestricted use, distribution, and reproduction in any medium, provided the original work is properly cited.

\begin{abstract}
This paper investigates the unsteady hydromagnetic-free convection of an incompressible electrical conducting Boussinesq's radiating fluid past a moving vertical plate in an optically thin environment with the Navier slip, viscous dissipation, and Ohmic and Newtonian heating. The nonlinear partial differential equations governing the transient problem are obtained and tackled numerically using a semidiscretization finite difference method coupled with Runge-Kutta Fehlberg integration technique. Numerical data for the local skin friction coefficient and the Nusselt number have been tabulated for various values of parametric conditions. Graphical results for the fluid velocity, temperature, skin friction, and the Nusselt number are presented and discussed. The results indicate that the skin friction coefficient decreases while the heat transfer rate at the plate surface increases as the slip parameter and Newtonian heating increase.
\end{abstract}

\section{Introduction}

The magnetohydrodynamic (MHD) thermal boundary layer flow over a moving plate has attracted considerable attention during the last few decades due to its numerous applications in industrial manufacturing processes such as hot rolling, wire drawing, glass-fiber and paper production, drawing of plastic films, metal and polymer extrusion, and metal spinning [1]. In all these processes, the quality of final product strongly depends on rate of cooling. An electrically conducting fluid subject to magnetic field is useful in controlling the rate of cooling. In addition, this type of flow has attracted the interest of many investigators in view of its applications in many engineering problems such as MHD generators, plasma studies, nuclear reactors, and geothermal energy extractions due to the effect of magnetic fields on the boundary layer flow control and on the performance of many systems using electrically conducting fluids [2]. Many studies have been reported for vertical, horizontal, and inclined plate in presence of a transverse magnetic field. The effects of magnetic field on boundary layer flow with heat and mass transfer past a stretching surface were investigated by Liu
[3]. Makinde [4] studied the effect of convective boundary condition on hydromagnetic buoyancy induced flow with heat and mass transfer over a vertical heated plate. The effects of heat transfer on MHD unsteady free convection flow past an infinite/semi-infinite vertical plate were analyzed by $[5,6]$. Moreover, many industrial and engineering processes occur at high temperatures and hence the knowledge of radiation heat transfer is essential for designing appropriate equipment [7]. When radiative heat transfer takes place, the electrically conducting fluid involved may be ionized due to the high operating temperature [8]. Hence, the effect of radiation on MHD flow and heat transfer problems has become industrially more important. Nandkeolyar et al. [9] have analyzed the effect of radiation on heat transfer in unsteady MHD natural convection flow of a dusty fluid past an impulsively moving vertical plate. Seini and Makinde [10] studied the radiation effects on the combined heat and mass transfer in MHD flow over an exponentially stretching surface. The radiation effects on MHD-free convection flow of an electrically conducting gray gas near equilibrium in the optically thin limit along an infinite vertical porous plate are studied by Seddeek and Aboeldahab [11]. Meanwhile, 
the problem of slip MHD flow with viscous dissipation past a moving surface has many important technological and industrial applications, especially in microelectromechanical systems (MEMS) such as micro-MHD pumps, micromixing of physiological samples, the flow of rarefied gases, emulsions, suspensions, foams, and polymer solutions. The linear slip condition at the solid surface was introduced by Navier [12] in his pioneering work. He postulated that the fluid velocity component tangential to the solid surface is proportional to the shear stress on the fluid-solid interface. Huang and Breuer [13] reported a direct experimental measurement of slip length in electrolyte solutions. Martin and Boyd [14] investigated the slip flow and heat transfer past a flat surface at constant wall temperature. Their results demonstrate that the boundary layer equations can be used to study flow at MEMS scale and provide useful information to study the effects of rarefaction on the shear stress and structure of the flow. Wang [15] studied the effect of slip flow on the heat transfer from a moving plate.

In spite of all these studies, the unsteady MHD convective heat transfer over a flat surface with the Navier slip in the presence of thermal radiation, viscous dissipation, and Ohmic and Newtonian heating has received little attention. Hence, the main objective of the present investigation is to consider the case of a convectively heated moving vertical plate with the Navier slip in the presence of thermal radiation, viscous and Ohmic heating when the magnetic field is imposed transversely on the plate surface. The classical model for radiation effect introduced by Cogley et al. [16] is employed and the nonlinear problem is tackled numerically using a semidiscretization finite difference method coupled with a Runge-Kutta-Fehlberg integration technique. The effects of different governing parameters on the momentum and heat transfer characteristics are explored and discussed in detail. To the best of our knowledge, the investigations of the proposed problem are new and the results have not been published before.

\section{Mathematical Analysis}

We consider the two-dimensional unsteady flow of an incompressible, viscous, and electrically conductive fluid past a moving vertical infinite plate with the Navier slip under the combined influence of a uniform transverse magnetic field and radiative heat transfer. It is assumed that there is no applied voltage, which implies the absence of an electric field. The transverse applied magnetic field and the magnetic Reynolds number are assumed to be very small so that the induced magnetic field and the Hall effect are negligible as shown in Figure 1.

The left surface of the plate is assumed to be heated by convection from a hot fluid at temperature $T_{f}$ which provides a heat transfer coefficient $h$. The $x$-axis is taken along the vertical plate and the $y$-axis is taken normal to the plate. The fluid properties are assumed to be constant except that the influence of density variation with temperature has been considered only in the body-force term of the linear momentum equation according to the Boussinesq

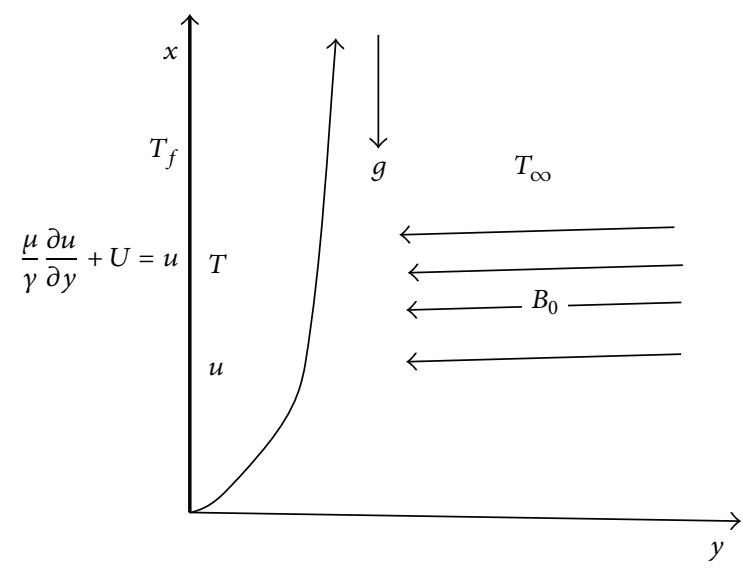

FIGURE 1: Flow configuration and coordinate system.

approximation. Under these assumptions, the dimensionless equations that describe the physical situation are given by $[5,6,8,10]$ as follows:

$$
\begin{gathered}
\frac{\partial u}{\partial t}=v \frac{\partial^{2} u}{\partial y^{2}}+g \beta\left(T-T_{\infty}\right)-\frac{\sigma B_{0}^{2} u}{\rho}, \\
\rho c_{p} \frac{\partial T}{\partial t}=k \frac{\partial^{2} T}{\partial y^{2}}-\frac{\partial q_{r}}{\partial y}+\mu\left(\frac{\partial u}{\partial y}\right)^{2}+\sigma B_{0}^{2} u^{2},
\end{gathered}
$$

where $v$ is the kinematic viscosity, $T_{\infty}$ is the free stream temperature, $U$ is the plate velocity, $k$ is the thermal conductivity coefficient, $c_{p}$ is the specific heat at constant pressure, $\beta$ is the thermal expansion coefficient, $\rho$ is the fluid density, $g$ is gravitational acceleration, and $\sigma$ is the fluid electrical conductivity. Following Cogley et al. [16], since the medium is optically thin with relatively low density and the radiation absorption coefficient $\varepsilon \ll 1$,

$$
\frac{\partial q_{r}}{\partial \bar{y}}=4 \varepsilon^{2}\left(T-T_{\infty}\right),
$$

where

$$
\varepsilon^{2}=\int_{0}^{\infty} K_{\lambda}\left(\frac{\partial e_{\lambda p}}{\partial T}\right) d \lambda
$$

$K_{\lambda}$ is the absorption coefficient, $\lambda$ is the wave length, and $e_{\lambda p}$ is the Planck function. The appropriate initial and boundary conditions at the plate surface and far into the fluid on the right surface may be written as [4]

$$
\begin{gathered}
u(y, 0)=0, \quad T(y, 0)=T_{\infty}, \quad \forall y \geq 0, \\
u(0, t)=U+\frac{\mu}{\gamma} \frac{\partial u}{\partial y}(0, t), \quad-k \frac{\partial T}{\partial y}(0, t)=h\left[T_{f}-T(0, t)\right], \\
u(\infty, t) \longrightarrow 0, \quad T(\infty, t) \longrightarrow T_{\infty}, \quad t>0,
\end{gathered}
$$

where $U$ is the plate uniform velocity, $\mu$ is the dynamic viscosity coefficient, and $\gamma$ is the Navier slip coefficient. The 
following dimensionless variables and quantities are introduced into the governing momentum and energy balance equations; that is,

$$
\begin{gathered}
\eta=\frac{y U}{v}, \quad \tau=\frac{t U^{2}}{v}, \quad w=\frac{u}{U}, \\
\theta=\frac{T-T_{\infty}}{T_{f}-T_{\infty}}, \quad \mathrm{Gr}=\frac{g \beta v\left(T_{f}-T_{\infty}\right)}{U^{3}}, \quad N=\frac{4 \varepsilon^{2} v}{\rho c_{p} U^{2}}, \\
M^{2}=\frac{\sigma B_{0}^{2} v}{\rho U^{2}}, \quad \mathrm{Ec}=\frac{U^{2}}{c_{p}\left(T_{f}-T_{\infty}\right)}, \quad \operatorname{Pr}=\frac{\mu c_{p}}{k}, \\
\mathrm{Bi}=\frac{h v}{k U}, \quad \delta=\frac{\rho U}{\gamma},
\end{gathered}
$$

and we obtain

$$
\begin{gathered}
\frac{\partial w}{\partial \tau}=\frac{\partial^{2} w}{\partial \eta^{2}}+\operatorname{Gr} \theta-M^{2} w \\
\operatorname{Pr} \frac{\partial \theta}{\partial \tau}=\frac{\partial^{2} \theta}{\partial \eta^{2}}-N \operatorname{Pr} \theta+\operatorname{Ec} \operatorname{Pr}\left(\frac{\partial w}{\partial \eta}\right)^{2}+\operatorname{Ec} \operatorname{Pr} M^{2} w^{2}
\end{gathered}
$$

with

$$
\begin{gathered}
w(\eta, 0)=0, \quad \theta(\eta, 0)=0, \quad \forall \eta \geq 0 \\
w(0, \tau)=1+\delta \frac{\partial w}{\partial \eta}(0, \tau), \quad \frac{\partial \theta}{\partial \eta}(0, \tau)=\operatorname{Bi}[\theta(0, \tau)-1] \\
w(\infty, \tau) \longrightarrow 0, \quad \theta(\infty, \tau) \longrightarrow 0, \quad \tau>0,
\end{gathered}
$$

where Pr represents the Prandtl number, Gr is the Grashof number, Ec is the Eckert number, $M$ is the Hartmann number, $N$ is the radiation parameter, $\mathrm{Bi}$ is the Biot number, and $\delta$ is the Navier slip parameter such that $\delta=0$ corresponds to no slip, while full lubrication is described in the limit $\delta \rightarrow$ $\infty$. The quantities of practical interest in this study are the skin friction coefficient $C_{f}$ which is defined as

$$
C_{f}=\frac{S_{w}}{\rho U^{2}}, \quad \mathrm{Nu}=\frac{v q_{w}}{U k\left(T_{f}-T_{\infty}\right)},
$$

where $S_{w}$ is the plate surface shear stress and $q_{w}$ is the heat flux from the plate surface which are given by

$$
S_{w}=-\left.\mu \frac{\partial u}{\partial y}\right|_{y=0}, \quad q_{w}=-\left.k \frac{\partial T}{\partial y}\right|_{y=0} .
$$

Substituting (9) into (8), we obtain

$$
C_{f}=-\frac{\partial w}{\partial \eta}(0, \tau), \quad \mathrm{Nu}=-\frac{\partial \theta}{\partial \eta}(0, \tau) .
$$

The set of (6) under the initial and boundary conditions (7)-(9) have been solved numerically by using the semidiscretization finite difference technique coupled with a RungeKutta-Fehlberg integration technique.

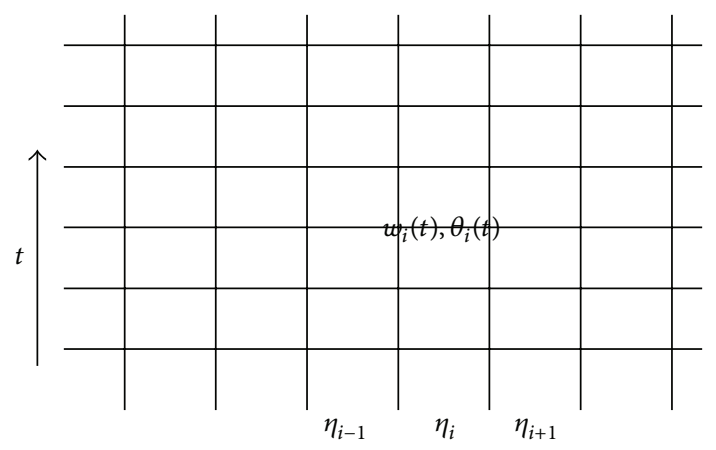

Figure 2: Computational domain with nodes.

\section{Numerical Procedure}

The semidiscretization finite difference technique known as method of line [17] is employed to tackle the model nonlinear initial boundary value problem in (6)-(9). The discretization is based on a linear Cartesian mesh and uniform grid on which finite differences are taken (see Figure 2). Firstly, a partition of the spatial interval $0 \leq \eta \leq \eta_{\max }$ is introduced. We divide it into $N$ equal parts and define grid size $\Delta \eta=1 / N$ and grid points $\eta_{i}=(i-1) \Delta \eta, 1 \leq i \leq N+1$.

The first and second spatial derivatives in (6) are approximated with second-order central finite differences. Let $w_{i}(t)$ and $\theta_{i}(t)$ be approximation of $w\left(\eta_{i}, t\right)$ and $\theta\left(\eta_{i}, t\right)$; then the semidiscrete system for the problem becomes

$$
\begin{aligned}
\frac{d w_{i}}{d \tau}= & \frac{\left(w_{i+1}-2 w_{i}+w_{i-1}\right)}{(\Delta \eta)^{2}}+\operatorname{Gr} \theta_{i}-M^{2} w_{i}, \\
\operatorname{Pr} \frac{d \theta_{i}}{d \tau}= & \frac{\left(\theta_{i+1}-2 \theta_{i}+\theta_{i-1}\right)}{(\Delta \eta)^{2}}-N \operatorname{Pr} \theta_{i} \\
& +\operatorname{Ec} \operatorname{Pr}\left(\frac{w_{i+1}-w_{i-1}}{2 \Delta \eta}\right)^{2}+\operatorname{Ec} \operatorname{Pr} M^{2} w_{i}^{2},
\end{aligned}
$$

with initial conditions

$$
w_{i}(0)=\theta_{i}(0)=0, \quad 1 \leq i \leq N+1 .
$$

The equations corresponding to the first and last grid points are modified to incorporate the boundary conditions as follows:

$$
\begin{aligned}
w_{1} & =\frac{\delta w_{2}+\Delta \eta}{\delta+\Delta \eta}, \quad \theta_{1}=\frac{\theta_{2}+\mathrm{Bi} \Delta \eta}{1+\mathrm{Bi} \Delta \eta}, \\
w_{N+1} & =\theta_{N+1}=0 .
\end{aligned}
$$

There is only one independent variable in (13), so they are first-order ordinary differential equations with known initial conditions. The resulting initial value problem can be easily solved iteratively using Runge-Kutta-Fehlberg integration technique [18] implemented on computer using Matlab. The maximum value of $\eta_{\max }$ to each group of parameters $M, \mathrm{Gr}, \mathrm{Pr}, \mathrm{Ec}, N, \mathrm{Bi}$, and $\delta$ is determined such that the values of the boundary conditions are satisfied with error less than 
$10^{-7}$. From the process of numerical computation, the local skin friction coefficient and the local Nusselt number in (12) are also worked out and their numerical values are presented graphically.

\section{Results and Discussion}

In order to gain insight into the thermal boundary layer development over the moving plate, the numerical calculations have been carried out for different values of parameters embedded in the flow system. The Prandtl number was taken to be in the range of $\operatorname{Pr}=0.71$, which corresponds to air at $20^{\circ} \mathrm{C}$ and $\operatorname{Pr}=7.1$ (water). The numerical values for local skin friction and the Nusselt number are computed for various values of the parameters $M, \mathrm{Bi}, N, \mathrm{Ec}, \delta, \mathrm{Gr}$, and $\mathrm{Pr}$. These results are presented in Table 1 . It is seen from the table that the effect of increasing values of $\mathrm{Bi}, \mathrm{Ec}, \delta$, and $\mathrm{Gr}$ is to decrease skin friction coefficient whereas increasing $M, N$, and Pr increases the skin friction coefficient. Further, the Nusselt number decreases on increasing the values of $\mathrm{Ec}, M$, and $\mathrm{Gr}$ but increases on increasing the values of $\mathrm{Bi}, N, \delta$, and $\operatorname{Pr}$.

4.1. Effects of Parameter Variation on Velocity Profiles. Figures 3-10 illustrate the effects of various parameters on the transient velocity profiles. Interestingly, for a given set of parameter values, the velocity profile increases in time until the corresponding steady state momentum boundary layer thickness is achieved as shown in Figure 3. For instance, the steady state velocity profile is achieved at $\tau \geq 4$ for the set of parameter values utilized in Figure 3. The transient velocity profile in the boundary layer for increasing values of $\mathrm{Gr}>0$ is presented in Figure 4. The thermal Grashof number signifies the relative effect of the thermal buoyancy (due to density differences) force to the viscous hydrodynamic force in the boundary layer flow. The positive values of $\mathrm{Gr}$ correspond to cooling of the plate by natural convection. It is observed that the transient velocity accelerates due to enhancement in the thermal buoyancy force, that is, free convection effects. As the buoyancy effects become relatively large due to increasing value of $\mathrm{Gr}$, the fluid velocity increases, reaching its peak value near the plate surface and then decreases monotonically to the zero-free stream value satisfying the far field condition. These results agree with the earlier results of Makinde [4] and Takhar et al. [8]. Figures 5-6 depict the effects of increasing $\mathrm{Bi}$ and $\mathrm{Ec}$ on the transient velocity profiles. An increase in momentum boundary layer thickness is observed with increasing Newtonian and viscous heating. This is expected since the fluid on the right surface of the plate becomes lighter and flow faster. The velocity profiles for different values of the Hartmann number $M$ are illustrated in Figure 7. As $M$ increases, the rate of transport is considerably reduced. This clearly indicates that the transverse magnetic field opposes the transport phenomena. The presence of magnetic field in an electrically conducting fluid produces a Lorentz force which acts against the flow leading to a decrease in the momentum boundary layer thickness. This observation is in agreement with the earlier results as reported by Ishak

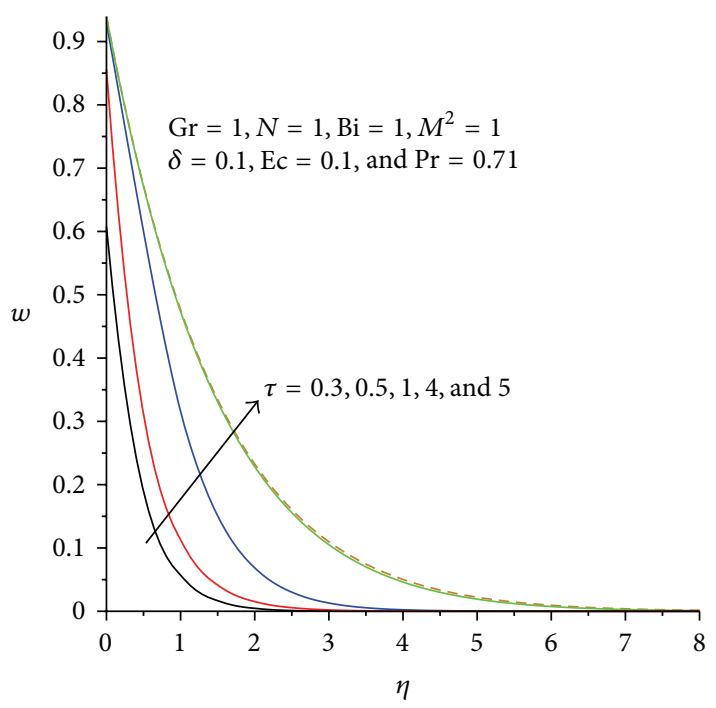

FIGURE 3: Velocity profiles with increasing time.

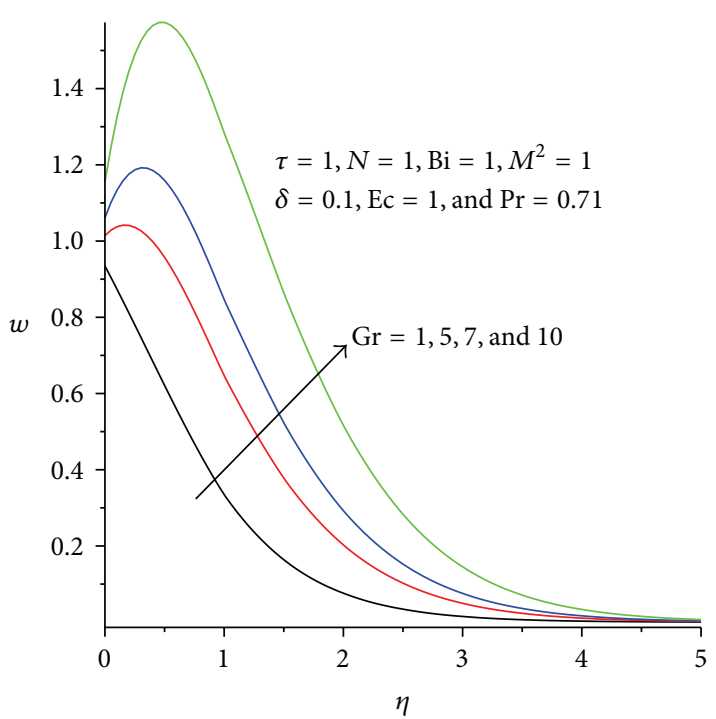

FIGURE 4: Velocity profiles with increasing Gr.

[6]. Similar trend is observed in Figures 8, 9, and 10 with increasing values of $\delta, N$, and Pr. As the Navier slip on the plate surface increases, plate motion reduces and the boundary layer thickness decreases. The transient velocity decreases with increasing radiative heat loss. As the Prandtl number increased from 0.71 (Air) to 7.1 (water), a clear decrease in the flow velocity is observed. This may be attributed to the fact that Pr encapsulates the ratio of momentum diffusivity to thermal diffusivity for a given fluid. It is also the product of dynamic viscosity and specific heat capacity divided by thermal conductivity. Higher Pr fluids will therefore possess higher viscosities leading to a decrease in the momentum boundary layer thickness.

4.2. Effects of Parameter Variation on Temperature Profiles. Figures 11-17 illustrate the effects of different parameter 
TABLE 1: Computation showing the $C_{f}$ and $\mathrm{Re}_{x}^{-1} \mathrm{Nu}$ for various values of embedded parameter.

\begin{tabular}{|c|c|c|c|c|c|c|c|c|}
\hline$\delta$ & $\mathrm{Gr}$ & $N$ & $M^{2}$ & $\mathrm{Bi}$ & Ec & $\operatorname{Pr}$ & $C_{f}$ & $\mathrm{Re}_{x}^{-1} \mathrm{Nu}$ \\
\hline 0.1 & 0.1 & 1.0 & 1.0 & 0.1 & 0.1 & 0.71 & 0.901016 & 0.085017 \\
\hline 0.3 & 0.1 & 1.0 & 1.0 & 0.1 & 0.1 & 0.71 & 0.763076 & 0.086251 \\
\hline 0.5 & 0.1 & 1.0 & 1.0 & 0.1 & 0.1 & 0.71 & 0.661702 & 0.087026 \\
\hline 0.1 & 0.5 & 1.0 & 1.0 & 0.1 & 0.1 & 0.71 & 0.868688 & 0.085038 \\
\hline 0.1 & 1.0 & 1.0 & 1.0 & 0.1 & 0.1 & 0.71 & 0.828146 & 0.085055 \\
\hline 0.1 & 0.1 & 2.0 & 1.0 & 0.1 & 0.1 & 0.71 & 0.904190 & 0.089414 \\
\hline 0.1 & 0.1 & 3.0 & 1.0 & 0.1 & 0.1 & 0.71 & 0.905498 & 0.091414 \\
\hline 0.1 & 0.1 & 1.0 & 3.0 & 0.1 & 0.1 & 0.71 & 1.469844 & 0.081765 \\
\hline 0.1 & 0.1 & 1.0 & 5.0 & 0.1 & 0.1 & 0.71 & 1.821755 & 0.079920 \\
\hline 0.1 & 0.1 & 1.0 & 1.0 & 1.0 & 0.1 & 0.71 & 0.880522 & 0.434981 \\
\hline 0.1 & 0.1 & 1.0 & 1.0 & 5.0 & 0.1 & 0.71 & 0.865823 & 0.685971 \\
\hline 0.1 & 0.1 & 1.0 & 1.0 & 0.1 & 0.5 & 0.71 & 0.889648 & 0.067568 \\
\hline 0.1 & 0.1 & 1.0 & 1.0 & 0.1 & 1.0 & 0.71 & 0.875418 & 0.045849 \\
\hline 0.1 & 0.1 & 1.0 & 1.0 & 0.1 & 0.1 & 3.0 & 0.903388 & 0.087302 \\
\hline 0.1 & 0.1 & 1.0 & 1.0 & 0.1 & 0.1 & 7.1 & 0.903856 & 0.087302 \\
\hline
\end{tabular}

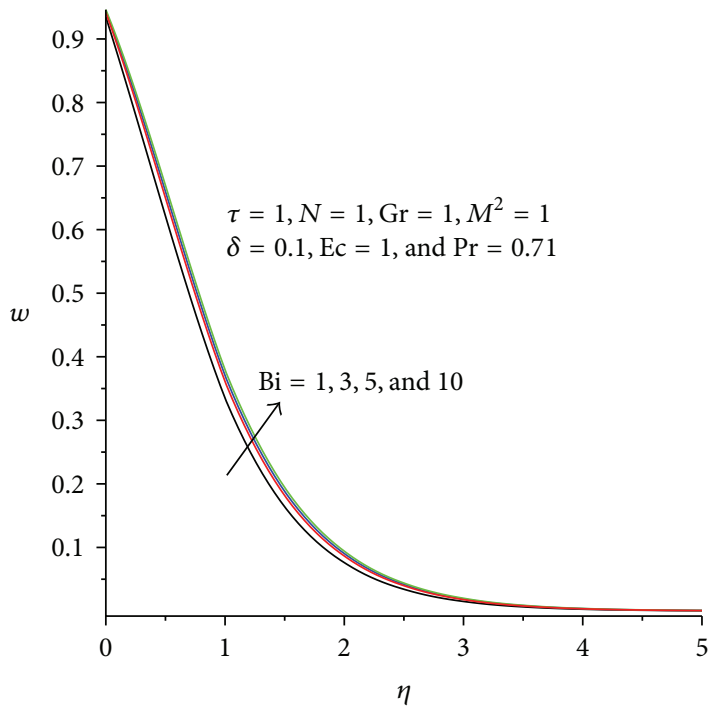

FIgURE 5: Velocity profiles with increasing Bi.

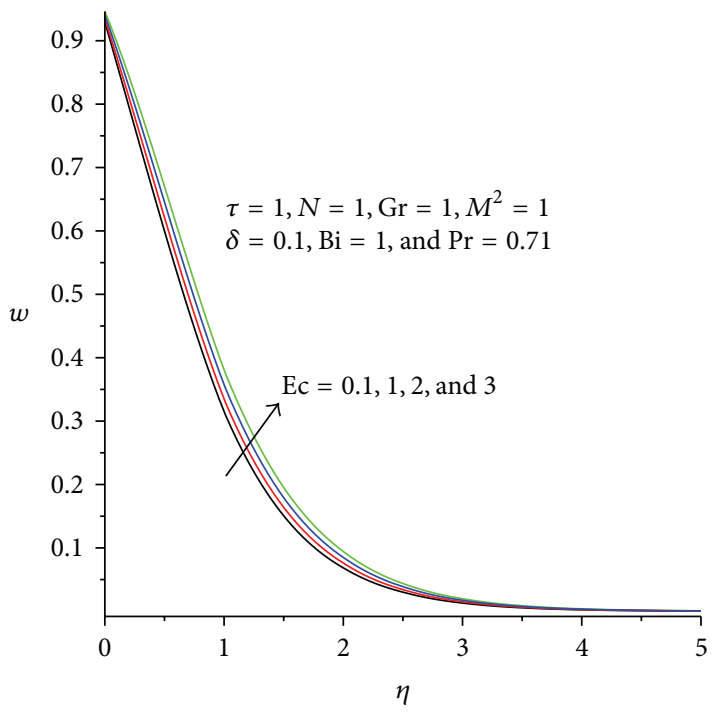

Figure 6: Velocity profiles with increasing Ec. variations on the temperature profiles. It is seen from all the figures that the transient temperature is maximum at the convectively heated plate surface and decreases exponentially to free stream zero value satisfying the boundary conditions. In Figure 11, we observed that the thermal boundary layer thickness increases with time until the steady state profile is achieved for a given set of parameter values. It is noteworthy that, for the set of parameter values utilized in Figure 11, the steady state temperature profile is achieved at $\tau \geq$ 4. Figure 12 depicts the effects of increasing Gr $>0$ on the thermal boundary layer. As thermal buoyancy force increases, heat is conducted away from the vertical plate into the fluid which increases temperature and thereby enhances the thermal boundary layer thickness. It is noted that the fluid temperature increases with an increase in magnetic field intensity, that is, as parameter $M$ increases. This may be attributed to the effect of Ohmic heating within the boundary layer region due to the imposed magnetic field as shown in Figure 13. It is evident from Figures 14-15 that the thermal boundary layer thickness increases as Biand Ecincrease. This is expected, since both Newtonian heating due to increasing the Biot number and viscous heating due to increasing the Eckert number constitute additional internal heat generation within the flow system leading to elevation in temperature profiles. Figure 16 reveals the effects of $N$ on the temperature profiles for the conducting air. It is evident from the figure that the temperature decreases with an increase in radiationconduction for air. All profiles decay exponentially from 


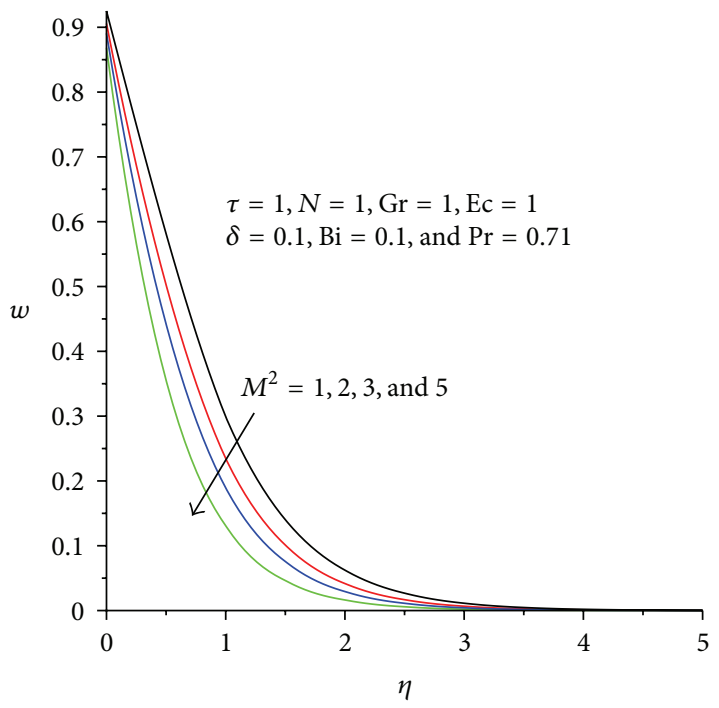

FIGURE 7: Velocity profiles with increasing $M$.

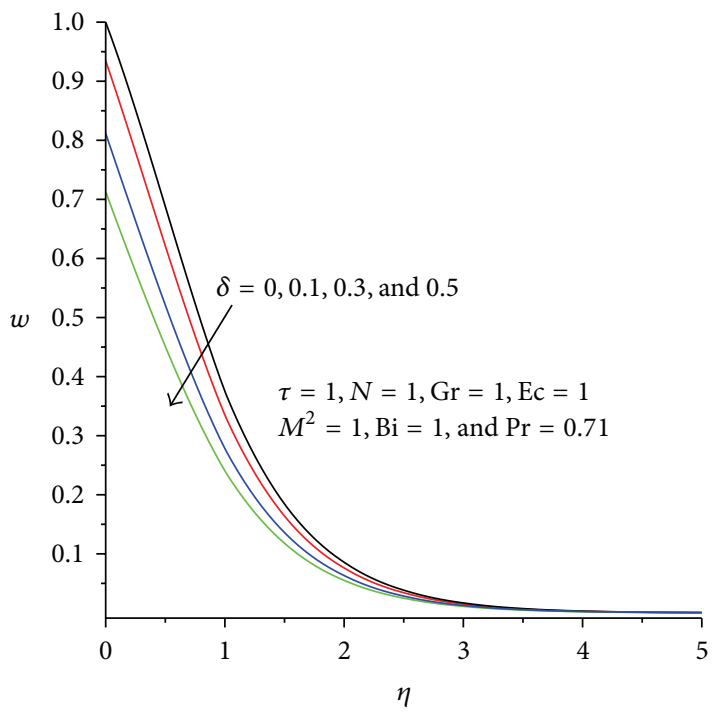

FIGURE 8: Velocity profiles with increasing $\delta$.

maximum value to zero in the free stream. These results agree with the earlier results of Seini and Makinde [10] and Seddeek and Aboeldahab [11]. In Figure 17, it is noticed that the Navier slip $(\delta)$ causes a decrease in the fluid temperature leading to a decaying thermal boundary layer thickness. Figure 18 shows that the fluid temperature is reduced monotonically when the Prandtl number is increased. As the smaller values of the Prandtl number are equivalent to the increase in the thermal conductivity of the fluid, heat is able to diffuse away from the heated surface more rapidly than for higher values of the Prandtl number. Hence, higher Prandtl's number results in thinner thermal boundary layer due to lower thermal conductivity.

4.3. Skin Friction and the Nusselt Number. Figures 19-20 depict the skin friction profiles at the plate surface with

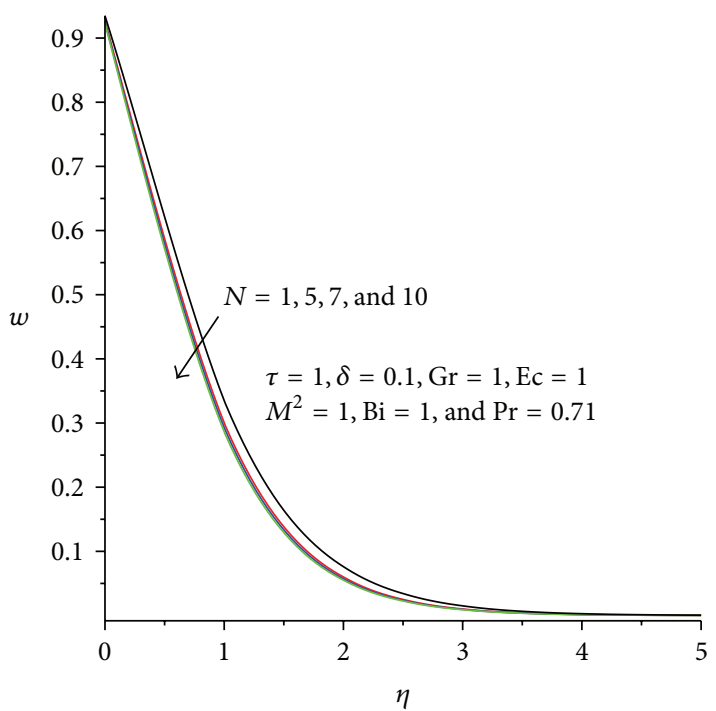

FIGURE 9: Velocity profiles with increasing $N$.

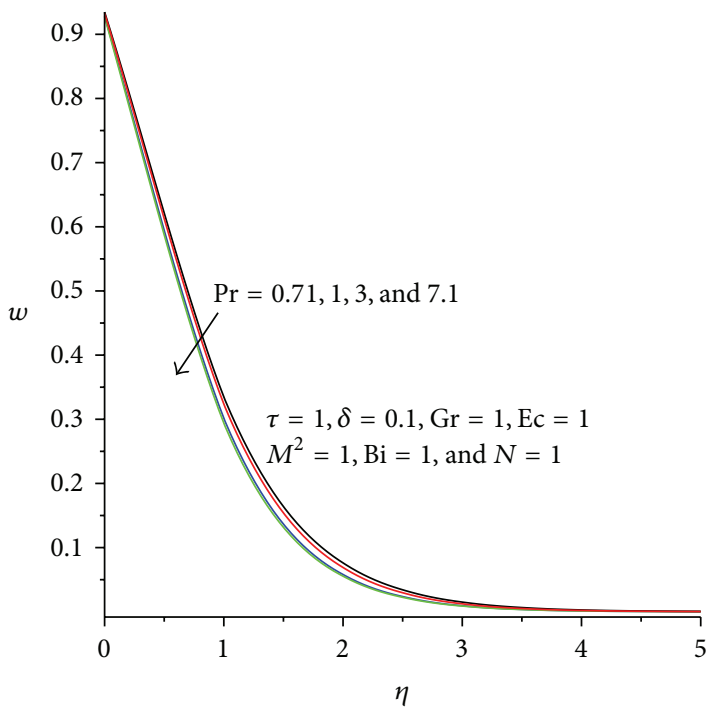

FIGURE 10: Velocity profiles with increasing Pr.

increasing values of embedded parameters. It is interesting to note that the velocity gradient at the plate surface increases with increasing magnetic field intensity, thermal radiation, and the Prandtl number and, consequently, the skin friction at the plate surface increases, whereas the effects of increasing the Navier slip, buoyancy force, and Newtonian and viscous heating are to decrease the velocity gradient at the plate surface, leading to a decrease in the skin friction as shown in Figures 19-20. In Figures 21-22, we observed that the rate of heat transfer at the plate surface increases with an increase in the intensity of the Navier slip, thermal radiation, Newtonian heating, and the Prandtl number. This may be attributed to a rise in the temperature gradient at the plate surface as $\mathrm{Bi}, N$, $\delta$, and Pr increase. However, a decrease in the temperature gradient at the plate surface occurs with increasing intensity 


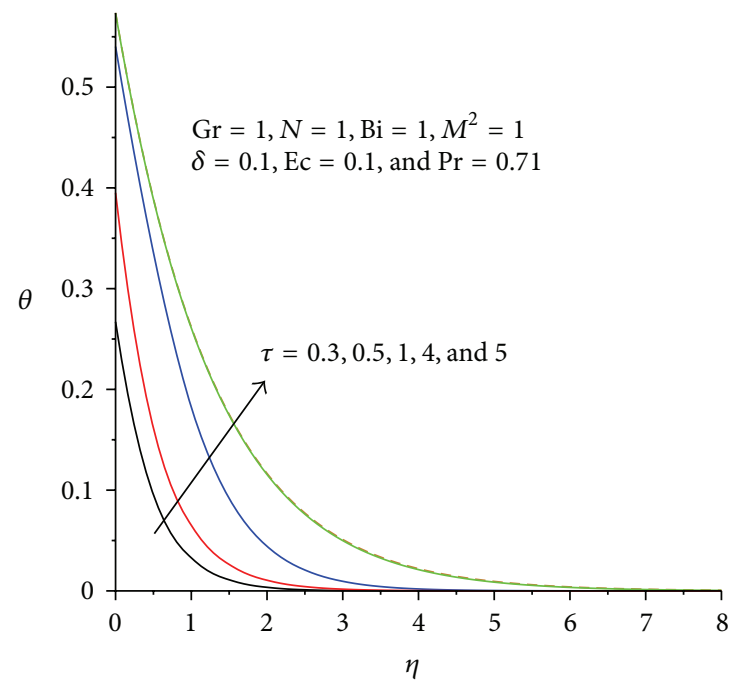

FIgURE 11: Temperature profiles with increasing time.

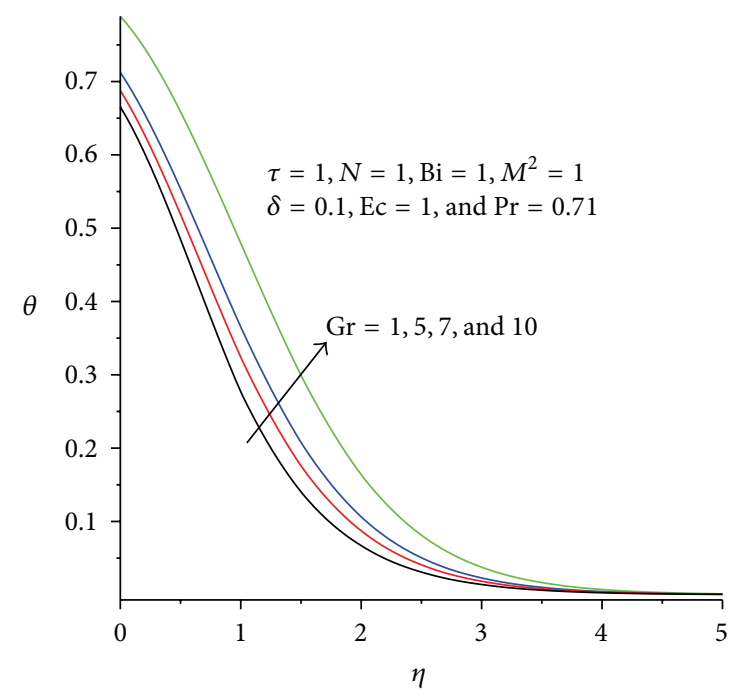

FigURE 12: Temperature profiles with increasing Gr.

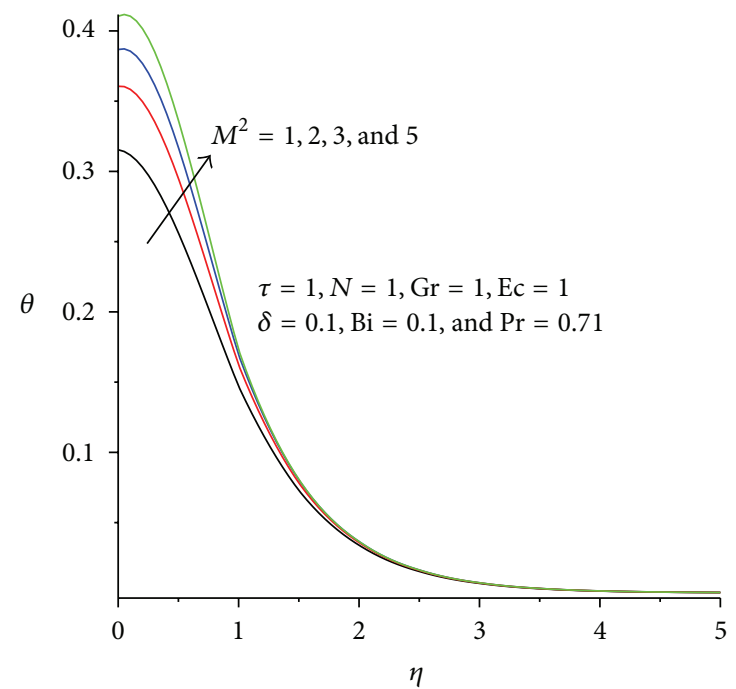

FIgURE 13: Temperature profiles with increasing $M$.

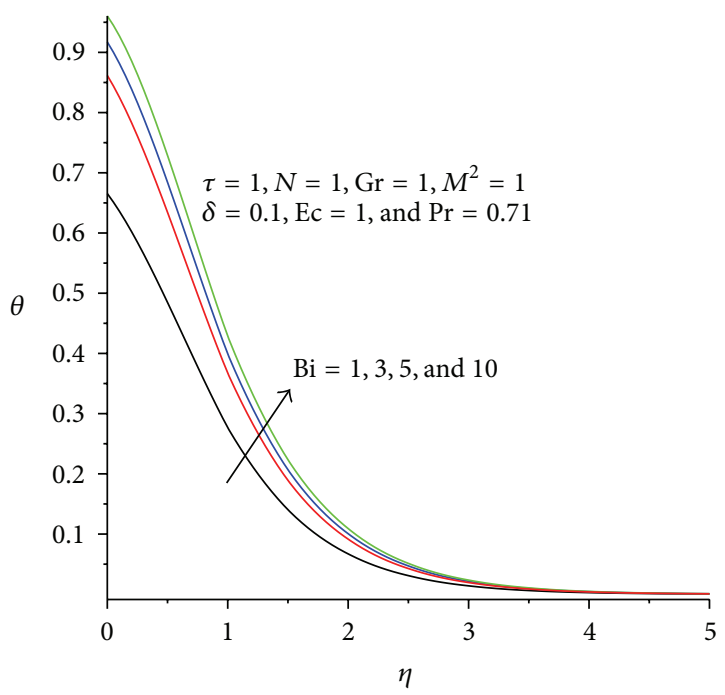

FIgURE 14: Temperature profiles with increasing Bi.

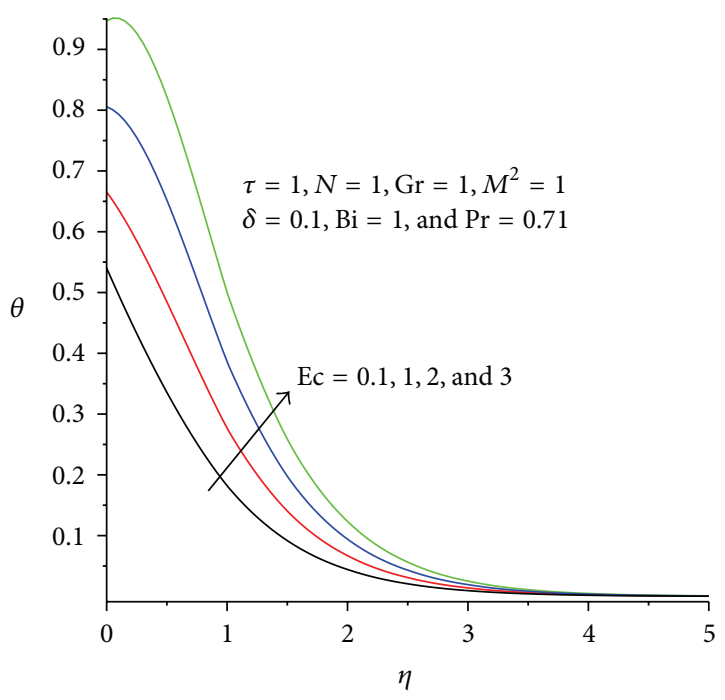

FIgURE 15: Temperature profiles with increasing Ec.

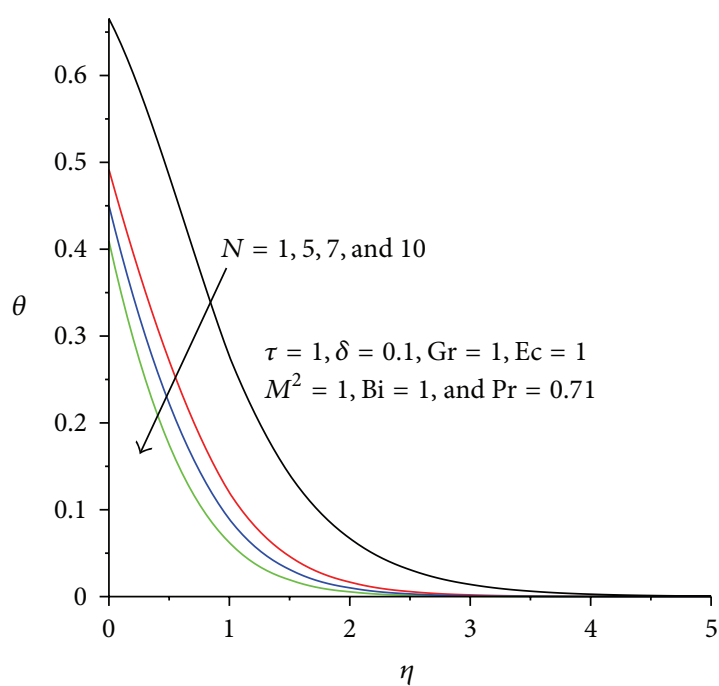

FIGURE 16: Temperature profiles with increasing $N$. 


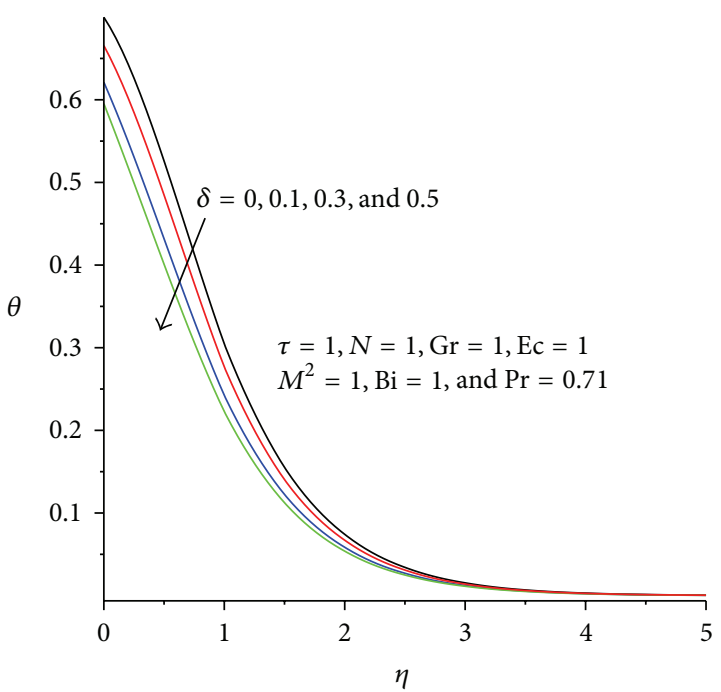

Figure 17: Temperature profiles with increasing $\delta$.

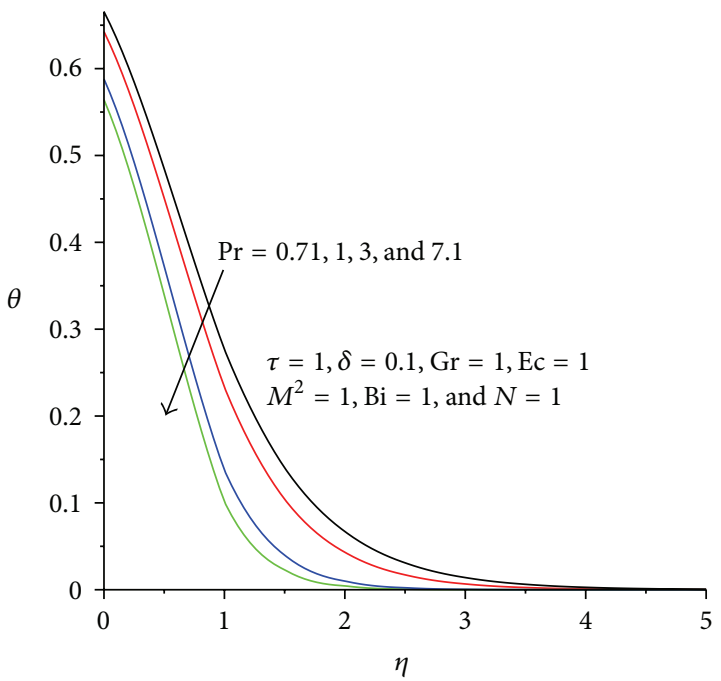

FIgURE 18: Temperature profiles with increasing Pr.

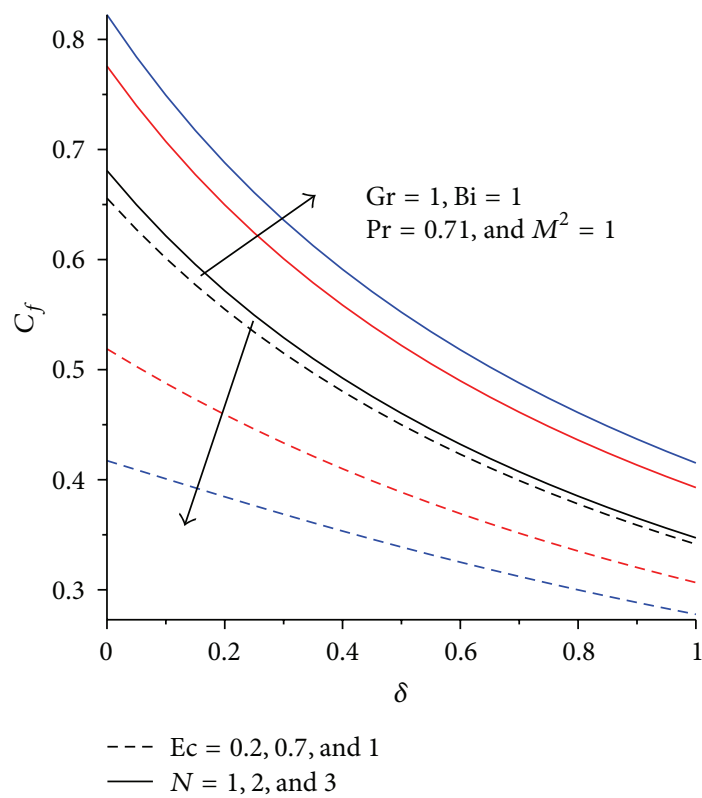

FIGURE 19: Skin friction with increasing Ec, $N$, and $\delta$.

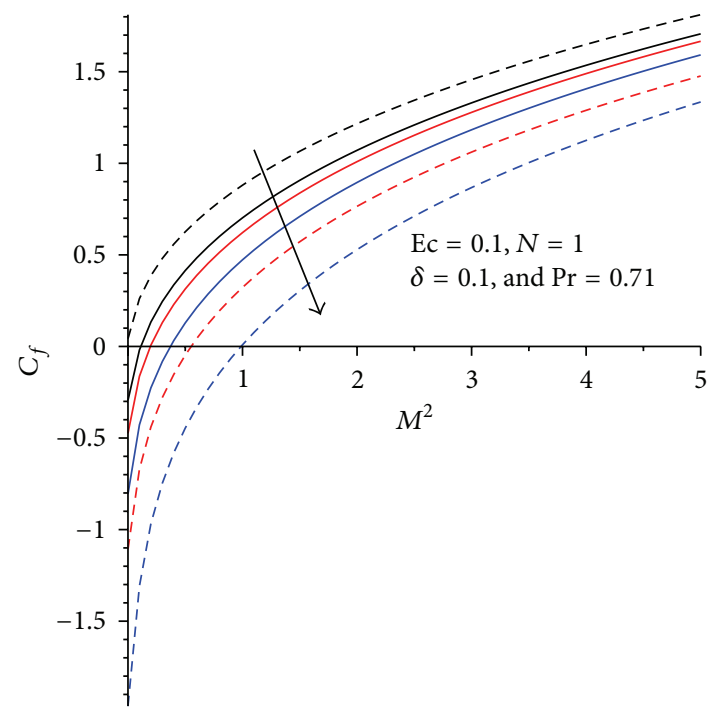

- $\mathrm{Bi}=0.5,1$, and 5

$\mathrm{Gr}=0.1,2$, and 3

FIGURE 20: Skin friction with increasing $M, \mathrm{Bi}$, and $\mathrm{Gr}$.

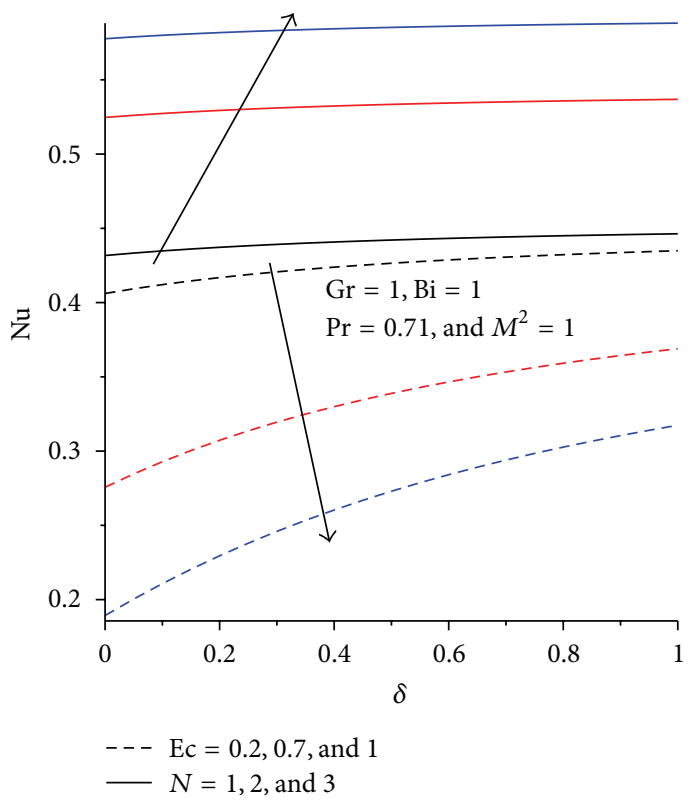

Figure 21: The Nusselt number with increasing Ec, $N$, and $\delta$.

of magnetic field, buoyancy force, and viscous dissipation, leading to a fall in the Nusselt number.

\section{Conclusions}

A theoretical analysis is performed to study the unsteady free convection-radiation MHD flow over a convectively heated moving vertical plate with the Navier slip and viscous and Ohmic heating. The nonlinear model problem is tackled numerically using a semidiscretization finite difference method coupled with Runge-Kutta-Fehlberg integration 


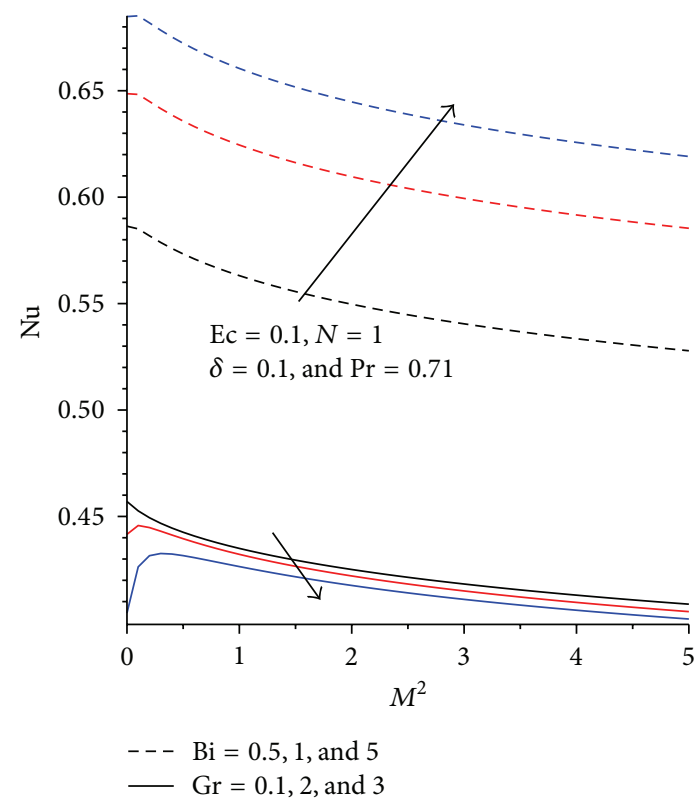

FIgURE 22: The Nusselt number with increasing $M, \mathrm{Bi}$, and $\mathrm{Gr}$.

technique. Some of the important conclusions of the study are as follows.

(i) Both the velocity and the temperature profiles increase with time until the corresponding steady state is achieved for a given set of parameter values.

(ii) The momentum boundary layer thickness increases with increasing values of $\mathrm{Gr}, \mathrm{Bi}$, and $\mathrm{Ec}$ and decreases with increasing values of $M, N, \delta$, and $\operatorname{Pr}$.

(iii) The thermal boundary layer thickness increases with increasing values of $M, \mathrm{Gr}, \mathrm{Bi}$, and $\mathrm{Ec}$ and decreases with increasing values of $N, \delta$, and $\operatorname{Pr}$.

(iv) Increasing values of $\mathrm{Bi}, \mathrm{Ec}, \delta$, and $\mathrm{Gr}$ decreases skin friction coefficient whereas increasing values of $M, N$, and Pr increases the skin friction coefficient.

(v) The Nusselt number decreases on increasing the values of Ec, $M$, and $\mathrm{Gr}$ but increases on increasing the values of $\mathrm{Bi}, N, \delta$, and $\operatorname{Pr}$.

\section{Nomenclature}

Bi: Biot's number

$B_{0}$ : Magnetic field strength

$C_{f}$ : Skin friction coefficient

$c_{p}$ : Specific heat at constant pressure

Ec: Eckert's number

Gr: Grashof's number g: Gravitational acceleration

$h$ : Heat transfer coefficient

$k$ : $\quad$ Thermal conductivity

$M: \quad H a r t m a n n ' s$ number

$N$ : Radiation parameter

Nu: Local Nusselt's number

Pr: Prandtl's number

$t$ : Time

T: Temperature

$T_{f}$ : Hot fluid temperature

$T_{\infty}$ : Free stream temperature

$u$ : Velocity component

$U$ : Plate velocity

$w$ : Dimensionless velocity

$(x, y)$ : Coordinates.

\section{Greek Symbols}

$\beta$ : Thermal expansion coefficient

$\delta$ : Navier's slip parameter

$\varepsilon$ : Radiation absorption coefficient

$\eta$ : Dimensionless coordinate

$\tau$ : Dimensionless time

$\theta$ : Dimensionless temperature

$\mu$ : Dynamic viscosity

$\gamma$ : Slip coefficient

$\sigma$ : Electrical conductivity

$v$ : Kinematic viscosity.

\section{Conflict of Interests}

The authors declare that there is no conflict of interests regarding the publication of this paper.

\section{References}

[1] R. Moreau, Magnetohydrodynamics, Kluwer Academic Publishers, Dordrecht, The Netherlands, 1990.

[2] J. Hartmann and F. Lazarus, Kongelige Danske Videnskabernes Selskabs, Mat-Fys Medd, 1937.

[3] I.-C. Liu, "A note on heat and mass transfer for a hydromagnetic flow over a stretching sheet," International Communications in Heat and Mass Transfer, vol. 32, no. 8, pp. 1075-1084, 2005.

[4] O. D. Makinde, "Similarity solution of hydromagnetic heat and mass transfer over a vertical plate with a convective surface boundary condition," International Journal of Physical Sciences, vol. 5, no. 6, pp. 700-710, 2010.

[5] M. A. Hossain and A. C. Mandal, "Mass transfer effects on the unsteady hydromagnetic free convection flow past an accelerated vertical porous plate," Journal of Physics D: Applied Physics, vol. 18, no. 7, article 003, pp. L63-L69, 1985.

[6] A. Ishak, "Unsteady MHD flow and heat transfer over a stretching plate," Journal of Applied Sciences, vol. 10, no. 18, pp. 2127-2131, 2010

[7] M. Q. Brewster, Thermal Radiative Transfer and Properties, John Wiley \& Sons, New York, NY, USA, 1992.

[8] H. S. Takhar, R. S. R. Gorla, and V. M. Soundalgekar, "Radiation effects on MHD free convection flow of a gas past a semi-infinite vertical plate," International Journal of Numerical Methods for Heat and Fluid Flow, vol. 6, no. 2, pp. 77-83, 1996. 
[9] R. Nandkeolyar, G. S. Seth, O. D. Makinde, P. Sibanda, and M. S. Ansari, "Unsteady hydromagnetic natural convection flow of a dusty fluid past an impulsively moving vertical plate with ramped temperature in the presence of thermal radiation," ASME-Journal of Applied Mechanics, vol. 80, no. 6, Article ID 061003, 9 pages, 2013.

[10] Y. I. Seini and O. D. Makinde, "MHD boundary layer due to exponentially stretching surface with radiation and chemical reaction," Mathematical Problems in Engineering, vol. 2013, Article ID 163614, 7 pages, 2013.

[11] M. A. Seddeek and E. M. Aboeldahab, "Radiation effects on unsteady MHD free convection with Hall current near an infinite vertical porous plate," International Journal of Mathematics and Mathematical Sciences, vol. 26, no. 4, pp. 249-255, 2001.

[12] C. L. M. H. Navier, Mémoire Sur Les Lois Du Mouvement Des fluides, Mémoires de l'Académie des sciences, 1823.

[13] P. Huang and K. S. Breuer, "Direct measurement of slip length in electrolyte solutions," Physics of Fluids, vol. 19, no. 2, Article ID 028104, 2007.

[14] M. J. Martin and I. D. Boyd, "Momentum and heat transfer in a laminar boundary layer with slip flow," Journal of Thermophysics and Heat Transfer, vol. 20, no. 4, pp. 710-719, 2006.

[15] C. Y. Wang, "Stagnation slip flow and heat transfer on a moving plate," Chemical Engineering Science, vol. 61, no. 23, pp. 76687672, 2006.

[16] A. C. Cogley, W. G. Vincent, and S. E. Giles, "Differential approximation to radiative heat transfer in a non-grey gas near equilibrium," American Institute of Aeronautics and Astronautics, vol. 6, no. 3, pp. 551-553, 1968.

[17] K. W. Morton and D. F. Mayers, Numerical Solution of Partial Differential Equations: An Introduction, Cambridge University Press, 2005.

[18] T. Y. Na, Computational Methods in Engineering Boundary Value Problems, Academic Press, New York, NY, USA, 1979. 


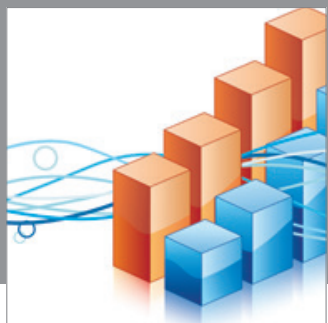

Advances in

Operations Research

mansans

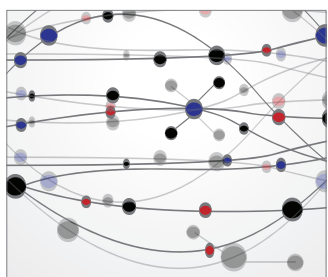

The Scientific World Journal
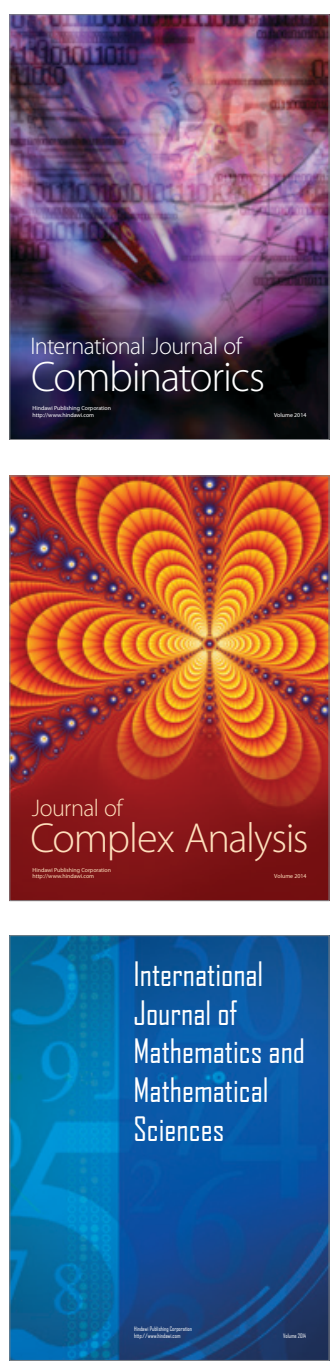
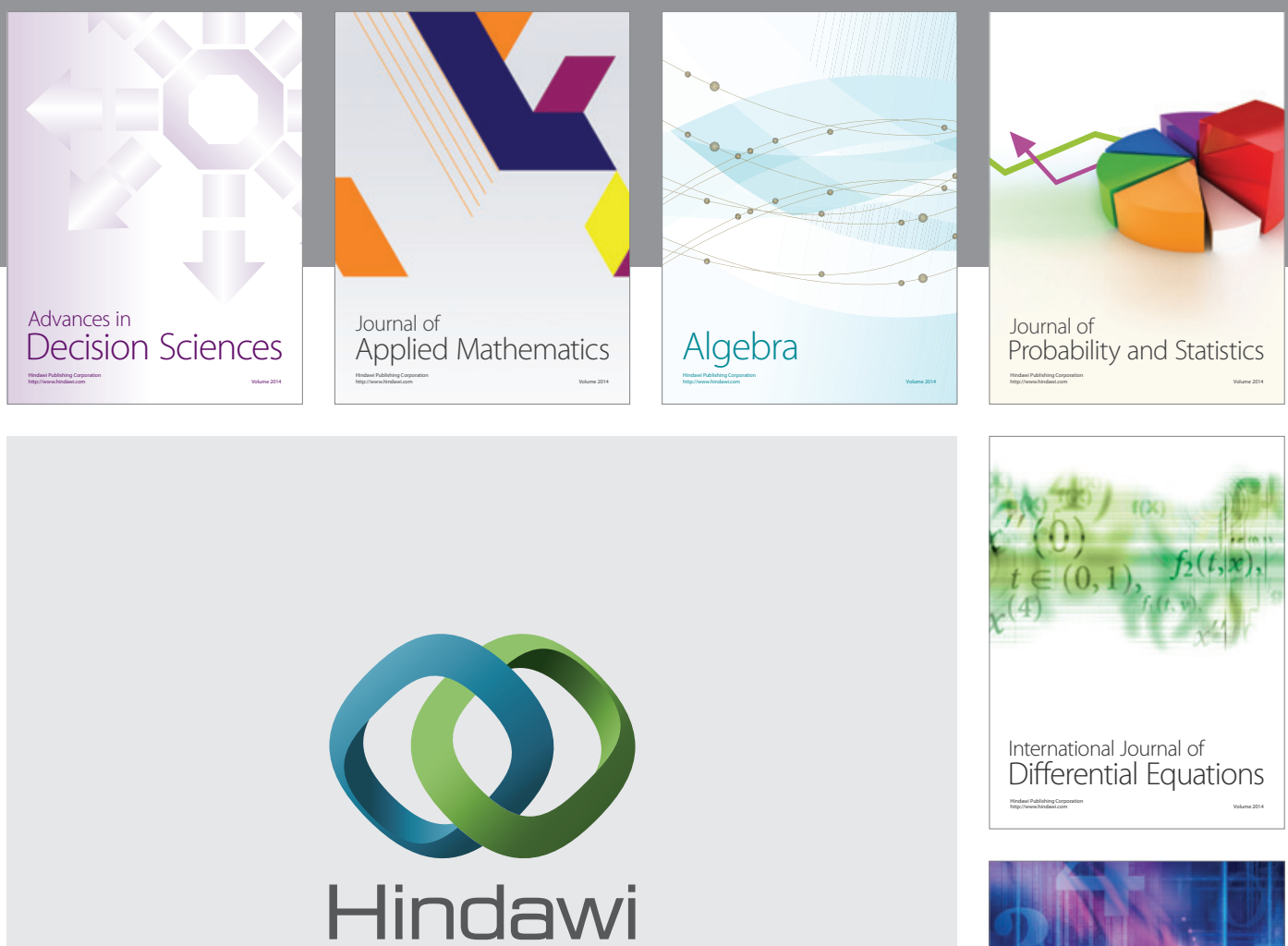

Submit your manuscripts at http://www.hindawi.com
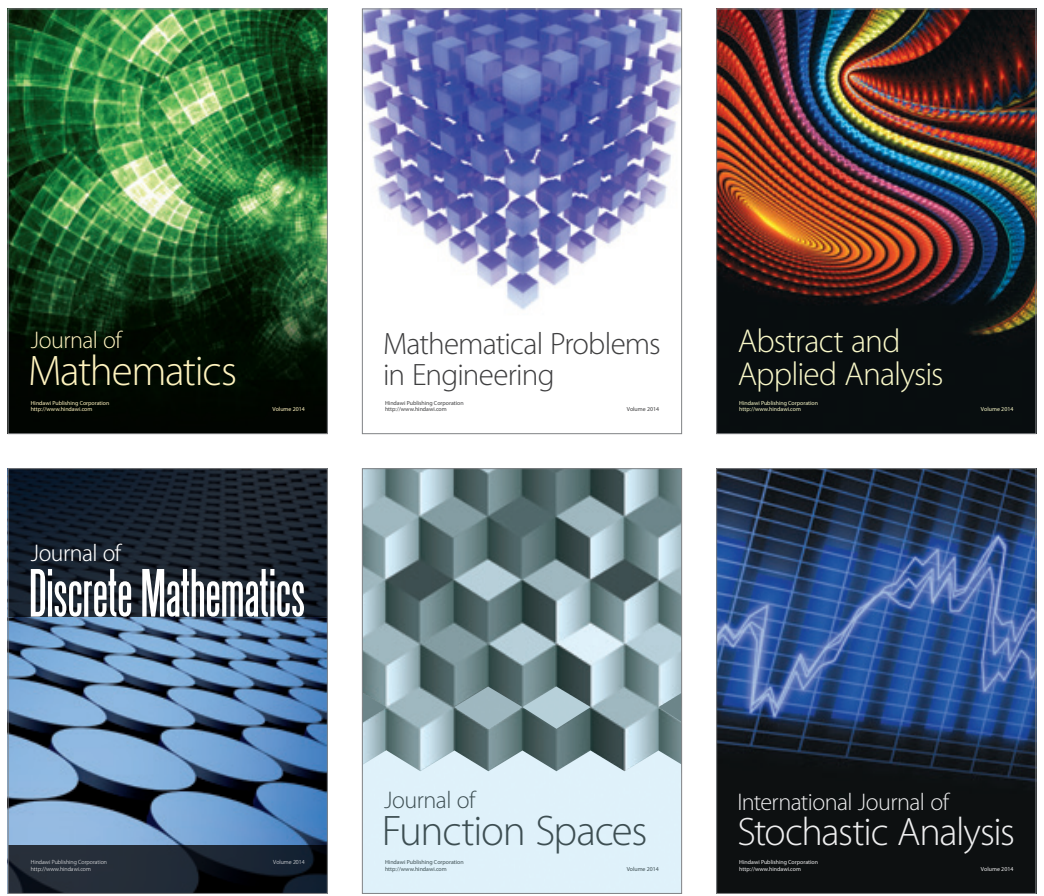

Journal of

Function Spaces

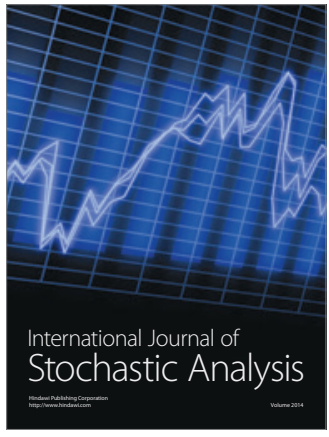

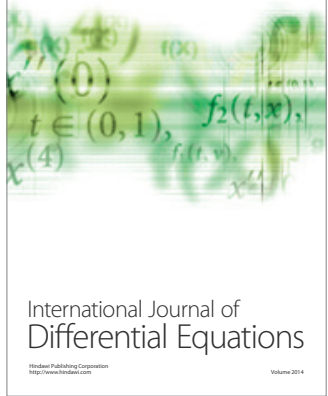
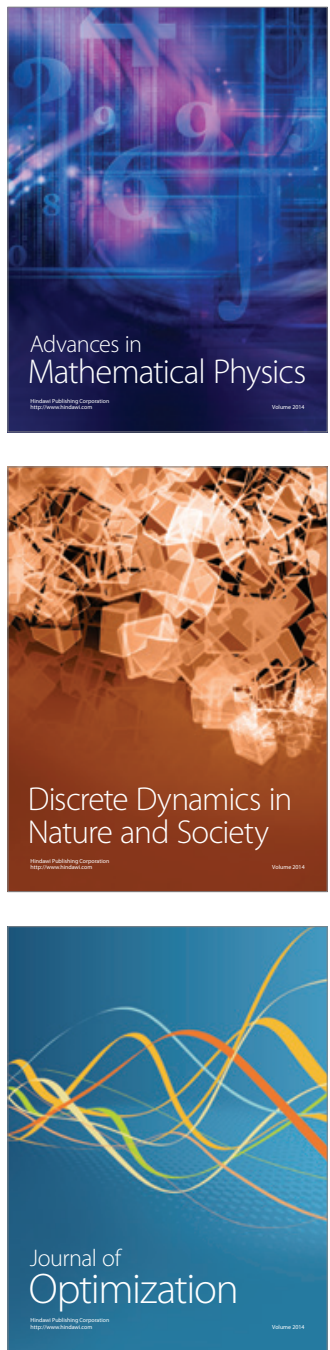